\title{
Dip Angle Effect on the Main Roof First Fracture and Instability in a Fully-Mechanized Workface of Steeply Dipping Coal Seams
}

\author{
Zhen Wei $\mathbb{D}^{1,2}$ Ke Yang $\mathbb{D}^{1,2,3}$ Xiaolou Chi $\mathbb{D}^{1,2}$ Wenjie Liu, ${ }^{1,2}$ and Xinyuan Zhao $\mathbb{D}^{1,2}$ \\ ${ }^{1}$ State Key Laboratory of Mining Response and Disaster Prevention and Control in Deep Coal Mines, \\ Anhui University of Science and Technology, Anhui, Huainan 232001, China \\ ${ }^{2}$ Key Laboratory of Mining Coal Safety and Construction Efficiency of Anhui Province, Ministry of Education, \\ Anhui University of Science and Technology, Huainan 232001, Anhui, China \\ ${ }^{3}$ Institute of Energy, Hefei Comprehensive National Science Center, Hefei 230031, Anhui, China \\ Correspondence should be addressed to Ke Yang; keyang2003@163.com
}

Received 6 January 2021; Revised 28 January 2021; Accepted 9 February 2021; Published 23 February 2021

Academic Editor: Feng Du

Copyright (c) 2021 Zhen Wei et al. This is an open access article distributed under the Creative Commons Attribution License, which permits unrestricted use, distribution, and reproduction in any medium, provided the original work is properly cited.

The fracture instability mechanism of the basic roof is the key to support selection and surrounding rock stability control, and it is also the guarantee of safe and efficient coal mining. By means of theoretical analysis and numerical calculation, the calculation model of basic roof of steeply dipping coal seams (SDCS) under linear load is established, the stress distribution expression of basic roof plate is deduced, the inclination effect of stress evolution of steeply dipping coal seams (SDCS) workface is analyzed, and the "sequential" weighting mechanism of workface is revealed. Based on the numerical simulation test, the evolution laws of vertical stress release and shear stress concentration of overlying strata in workface with different coal seam dip angles are obtained. The results show that there is shear stress arch in the overlying strata. With the increase of coal seam dip angle, the overlying strata are suddenly damaged under the action of shear stress. The roof is in the state of discontinuous movement due to its self-weight and overburden pressure. Support is affected by the discontinuous movement and moved along with the roof. The results of this study can be of theoretical reference to the control of SDCS.

\section{Introduction}

With a gradual reduction of coal resources and growing mining intensity, mining under complicated conditions has been increasing in recent years [1]. In particular, steeply dipping coal seams (SDCS) are regarded as difficult for mining [2-4]. However, with the development of fullymechanized mining theories, advancing research of equipment, and improved management in the workface, SDCS with shallow depth has gradually become the main coal seam in western China's mining areas. For example, the Sichuan Coal Industry Group Ltd., has succeeded in the trial mining in the Lvshuidong coal seam with a dip angle of $70^{\circ}$. The rock pressure pattern in the SDCS workface is influenced by a dip angle, which results in a significant difference from coal seam with a low dip angle during mining $[5,6]$. The available pressure control and technology theories focused on horizontal coal seams and coal seams with a shallow dip angle cannot guide the safe and efficient mining in SDCS. At present, roof falling, flying gangue in workface, and hydraulic support sliding are the major disasters in SDCS mining $[7,8]$ and are all directly related to roof stability. Therefore, the study of roof failure and movement is the prerequisite for safe and efficient mining in SDCS $[9,10]$.

Scholars have studied the general characteristics of surrounding rock movement and mine pressure behavior of longwall comprehensive mechanized mining stope under specific burial and mining conditions and preliminarily revealed the formation characteristics of surrounding rock stress field, roof caving and floor sliding characteristics, and gangue sliding filling characteristics $[11,12]$. Numerous field test results proved that mining in SDCS caused roof weighting in different zones in the workface, and the ground pressure became abnormal [13]. Studies of fracturing in 
different zones in the roof of the SDCS workface were conducted by different researchers and were focused on the failure, migration, and evolution law of the workface roof [14]. Several studies performed the analysis of the fracturing pattern of the main roof in the workface and the relationship between the support-surrounding rock $[15,16]$. Establish a mechanical model of stope roof based on elastic theory, analyze the evolution characteristics of basic roof fracture, and obtain fracture forms in different periods $[17,18]$. Based on the hinged rock block model, the limit position of the rotation instability of the hinged structure is studied, and the unique instability mode of the shallow-buried thin bedrock roof and the method for determining the working resistance of the support are proposed [19]. Based on the theoretical model of inclined coal seam stope, the stress distribution characteristics and fracture mechanism of basic roof strata during mining are analyzed [20-22].

Through the establishment of beam and slab model, the above research results made a systematic study on the roof fracture migration law of fully-mechanized working face, improved the understanding of the primary fracture instability of the basic roof, and enriched the theoretical system of surrounding rock control in coal mining. However, due to the complex and variability of mine geological conditions, it is impossible to comprehensively and accurately reflect the evolution of roof fractures during coal mining, and there is a lack of research on the influence of dip angle changes on the migration of overlying strata. Therefore, on the basis of the existing research, this paper adopts theoretical analysis methods to construct the basic roof mechanics model of high-inclined coal seam and studies the influence of the change of coal seam inclination angle on the initial breaking law of the basic roof of fully-mechanized coal face. The research results can provide a theoretical basis for formulating scientific prevention and control measures at the project site.

\section{Assumptions of the Main Roof Mechanical Model}

According to the assumption of a thin plate (or a slender body) in the elasticity theory [20], an elastic plate can be treated as a thin plate if the ratio between its thickness $h$ and length of its shortest side $l$ satisfies the following conditions:

$$
\left(\frac{1}{100} \sim \frac{1}{80}\right) \leq \frac{h}{l} \leq\left(\frac{1}{8} \sim \frac{1}{5}\right) \text {. }
$$

Below the first-fracture mining pressure in the longwall workface in SDCS is reaching, the main roof can be regarded as a thin plate since its thickness and length satisfy the above equation. Under the superposition of nonlinear load and mining stress, the basic roof of working face fractured and the first strata behavior occurred [23, 24].

Hard hanging roof zone appears in the goaf rear area after mining in the workface. Usually, the narrow coal pillar side and fault side are treated as simple boundaries. The solid coal side is treated as a clamped boundary [19], where deflection and rotation are zero. According to this, the influence law of coal seam dip angle on the evolution of basic roof stress in steeply dipping coal seam is analyzed.

\section{Rule of the First Fracture of the Main Roof}

3.1. Basic Equations of Thin Plate. As mining advances from the open-off cut, the main roof's exposed area gradually increases, and fracturing happens when the stress reaches the stratum's ultimate strength. The main roof in the SDCS workface is supported by integrated coal before fracturing. Since the coal seam's dip angle is relatively large, the false and immediate roofs fall to the bottom of goaf as mining proceeds. Therefore, a mechanical model of the main roof in SDCS, as shown in Figure 1, is elaborated in this study. Herein, the dip angle of the coal seam is $\alpha$, the $x$-axis is directed along the workface strike with a length of $a$, the $y$ axis is along the workface dip with a length of $b$, and the $z$ axis is normal to the roof and has positive downward direction.

Due to the impact of dip angle, the load from overburden rock that acts on the roof can be simplified as $P(y)$ that linearly changes along the dip (i.e., positive axis), which is expressed as

$$
P(y)=P_{0}-\gamma y \sin \alpha,
$$

where $\gamma$ is the average unit weight of the overburden rock and $\mathrm{P}_{0}$ is the overburden load in the roadway of workface. The later value, $P_{0}$, is decomposed into the force perpendicular to the roof denoted by $P_{1}=P(y) \cos \alpha$ and the force parallel to the roof denoted by $P_{2}=P(y) \sin \alpha$. Since the latter force component $P_{2}$ is much smaller than $P_{1}$ within the dip angle range under study, its effect is neglected, and the deflection function of the main roof under the linear overburden load is written as

$$
\omega_{1}(x, y)=A_{1}\left(y+\frac{b}{4}\right) \sin ^{2}\left(\frac{\pi x}{a}\right) \sin ^{2}\left(\frac{\pi y}{b}\right) .
$$

The following boundary conditions have to be satisfied:

$$
\begin{aligned}
\left(\omega_{1}\right)_{x=0, a} & =0, \\
\left(\omega_{1}\right)_{y=0, b} & =0, \\
\left(\frac{\partial \omega_{1}}{\partial x}\right)_{x=0, a} & =0, \\
\left(\frac{\partial \omega_{1}}{\partial y}\right)_{y=0, b} & =0 .
\end{aligned}
$$

According to the principle of minimum potential energy [25], the total potential energy of a thin plate under the linear overburden load is 


$$
E_{P}=\frac{D}{2} \iint\left\{\left(\frac{\partial^{2} \omega_{1}}{\partial x^{2}}+\frac{\partial^{2} \omega_{1}}{\partial y^{2}}\right)^{2}-2(1-\mu)\left[\frac{\partial^{2} \omega_{1}}{\partial x^{2}} \frac{\partial^{2} \omega_{1}}{\partial y^{2}}-\left(\frac{\partial^{2} \omega_{1}}{\partial x \partial y}\right)^{2}\right]\right\} \mathrm{d} x \mathrm{~d} y-\iint P_{1} \omega_{1} \mathrm{~d} x \mathrm{~d} y
$$

where $P_{1}$ is the overburden load perpendicular to the roof, $\omega_{1}$ is the deflection function of the main roof under linear overburden load, and $\mu$ is Poisson's ratio.
Since $\left(\partial E_{P} / \partial A_{1}\right)=0$, the deflection function coefficient can be calculated by

$$
A_{1}=\frac{(3 / 16) P_{0} \cos \alpha a b^{2}-(11 / 96) \gamma \sin \alpha \cos \alpha a b^{3}}{((D(1-\mu) b) / a)\left(\left(3 \pi^{2} / 8\right)+\left(\pi^{3} / 10\right)-\left(47 \pi^{4} / 120\right)\right)} .
$$

Substituting equation (6) into equation (3) yields the deflection function of the main roof with four fixed sides under the linear overburden load

$$
\omega_{1}(x, y)=\frac{\left((3 / 16) P_{0} \cos \alpha a b^{2}-(11 / 96) \gamma \sin \alpha \cos \alpha a b^{3}\right)(y+(b / 4)) \sin ^{2}(\pi x / a) \sin ^{2}(\pi y / b)}{\left[((D(1-\mu) b) / a)\left(\left(3 \pi^{2} / 8\right)+\left(\pi^{3} / 10\right)-\left(47 \pi^{4} / 120\right)\right)\right]},
$$

where $D$ is the bending stiffness of the thin plate, $D=\left(E h^{3} / 12\left(1-\mu^{2}\right)\right), E$ is the elastic modulus of the main roof, and $h$ is the main roof thickness.

Gangue filling in the goaf of SDCS is highly heterogeneous. Hence, the upper, middle, and bottom areas of the main roof have different stress states and kinematic movement patterns. It is assumed that falling gangue fills two-thirds of the total space of goaf of SDCS, the bottom area has good filling and is closer to the intact rock strength than the middle area, and the upper area has no filling, so a load of gangue filling on the main roof $P_{3}$ is derived as follows:

$$
P_{3}=P_{0}-\frac{3 y P_{0}}{2 b}, \quad 0 \leq y \leq \frac{2}{3} b .
$$

According to the principle of minimum potential energy, the deflection function of the main roof under gangue filling is

$$
\omega_{2}(x, y)=\frac{96 a^{2} b^{4} P_{0} y}{D(1-\mu) \pi^{3}\left(535 b^{4}+363 a^{2} b^{2}+315 a^{4}\right)} \sin ^{2}\left(\frac{\pi x}{a}\right) \sin ^{2}\left(\frac{\pi y}{b}\right) .
$$

Using equations (7) and (9) to derive $\omega=\omega_{1}-\omega_{2}$, one gets in the total deflection function of SDCS main roof under overburden pressure and gangue filling conditions.
3.2. Stress Expression. Using the coefficient and the relation between deflection and stress in the theory of thin elastic plate, stresses in the SDCS main roof can be derived as follows:

$$
\begin{aligned}
& \sigma_{x}=-\frac{E z\left(A_{1}-A_{2}\right)}{1-\mu^{2}}\left[\left(\frac{b \pi^{2}}{2 a^{2}}+\frac{2 \pi^{2} y}{a^{2}}\right) \cos \left(\frac{2 \pi x}{a}\right) \sin ^{2}\left(\frac{\pi y}{b}\right)+\frac{2 \pi \mu}{b} \sin ^{2}\left(\frac{\pi x}{a}\right) \sin \left(\frac{2 \pi y}{b}\right)+\sin ^{2}\left(\frac{\pi x}{a}\right) \cos \left(\frac{2 \pi y}{b}\right)\left(\frac{2 \pi^{2} \mu y}{b^{2}}+\frac{\pi^{2} \mu}{2 b}\right)\right], \\
& \sigma_{y}=-\frac{E z\left(A_{1}-A_{2}\right)}{1-\mu^{2}}\left[\frac{2 \pi}{b} \sin ^{2}\left(\frac{\pi x}{a}\right) \sin \left(\frac{2 \pi y}{b}\right)+\sin ^{2}\left(\frac{\pi x}{a}\right) \cos \left(\frac{2 \pi y}{b}\right)\left(\frac{2 \pi^{2} y}{b^{2}}+\frac{\pi^{2}}{2 b}\right)+\left(\frac{b \pi^{2} \mu}{2 a^{2}}+\frac{2 \pi^{2} \mu y}{a^{2}}\right) \cos \left(\frac{2 \pi x}{a}\right) \sin ^{2}\left(\frac{\pi y}{b}\right)\right], \\
& \tau_{x y}=-\frac{E z\left(A_{1}-A_{2}\right)}{1+\mu}\left[\frac{\pi}{a} \sin ^{2}\left(\frac{\pi y}{b}\right) \sin \left(\frac{2 \pi x}{a}\right)+\left(\frac{\pi^{2} y}{a b}+\frac{\pi}{4}\right) \sin \left(\frac{2 \pi y}{b}\right) \sin \left(\frac{2 \pi x}{a}\right)\right],
\end{aligned}
$$


where $0 \leq x \leq a, 0 \leq y \leq b$, and $-(h / 2) \leq z \leq(h / 2)$.

3.3. Stress Distribution in the Main Roof. During mining in the coal seam, when the roofs maximum tensile stress exceeds its tensile strength $\sigma_{t}$, the tensile fracture will occur [26]. According to equation (10), the distributions of $\sigma_{x}$ and $\sigma_{y}$ in the bottom floor are obtained and depicted in Figure 2.

In the calculation, all the loads that satisfy the inequality are taken as the loads of the overlying strata in the haulage roadway of the working face; the values of each parameter are as follows: Poisson's ratio is 0.25 , elastic modulus is
$30 \mathrm{GPa}$, thickness of basic roof rock is $6 \mathrm{~m}$, coal seam dip is $40^{\circ}$, strike length is $60 \mathrm{~m}$, and inclination length is $140 \mathrm{~m}$. The length and thickness of the basic roof meet the requirements of the elastic thin plate model. It keeps increasing the thin roof with the workface advance, while the upper area experiences compression $\longrightarrow$ tension $\longrightarrow$ compression and shows asymmetry as a whole along the dip of workface.

While $\sigma_{x}$ reaches its peak value at $x=(a / 2)$ and $y=0.56, \sigma_{y}$ reaches its peak value at $x=(a / 2)$ and $y=0.58 b$. The maximum stress can be calculated as follows:

$$
\begin{aligned}
& \sigma_{x \max }=-\frac{12 \mathrm{D} z\left(A_{1}-A_{2}\right)}{h^{3}}\left[\frac{1.615 \pi^{2} \mu+0.122 \pi \mu}{b}-9.425 \times 10^{-4} \times\left(\frac{b \pi^{2}+2.24 \pi^{2}}{2 a^{2}}\right)\right], \\
& \sigma_{y \max }=-\frac{12 \mathrm{D} z\left(A_{1}-A_{2}\right)}{h^{3}}\left[\frac{1.656 \pi^{2}+0.127 \pi}{b}-1.01 \times 10^{-3} \times\left(\frac{b \mu \pi^{2}+2.32 \mu \pi^{2}}{2 a^{2}}\right)\right] .
\end{aligned}
$$

As observed, $\sigma_{x \max }>\sigma_{y \max }$. Hence, $\sigma_{x}$ is the main factor controlling the fracturing instability of the overburden rock, while the dip angle of the coal seam only changes the rock's tensile stress (i.e., the ultimate span of workface). When the maximum tensile stress reaches the tensile strength limit at a certain point in the thin rock plate, the tensile fracture occurs, and gradually thin rock plate evolves into spatial surrounding rock structure.

Current studies show that when the tensile stress exceeds the shear stress, while the latter exceeds the compressive stress $\left(\sigma_{\text {tensile }}<\sigma_{\text {shear }}<\sigma_{\text {compressive }}\right)$, the tensile or shear failure is likely to take place in the stratum, and the failure pattern is determined by its tension and shear strengths as well as the stress within the stratum $[27,28]$. Therefore, the analysis of distributions of principal stress and shear stress on the main roof is of great significance. Relations between the roof stress components and principal stress, as well as shear stress, are described by the following equations:

$$
\begin{aligned}
& \sigma_{\max }=\frac{\sigma_{x}+\sigma_{y}}{2} \pm \sqrt{\frac{\left(\sigma_{x}-\sigma_{y}\right)^{2}}{2}+\tau_{x y}^{2}} \\
& \sigma_{\min } \\
& \tau_{\max }=\frac{\sigma_{\max }-\sigma_{\min }}{2} .
\end{aligned}
$$

Equations (12) and (13) determine the principal stresses $\sigma_{\max }$ and $\sigma_{\min }$ and shear stress $\tau_{\max }$ at any point in the thin floor where the four boundaries are fixed. The above stresses depend on the main roof s thickness $h$ and length-to-width ratio, overburden pressure, and coal seam dip angle $\alpha$. Hence, the overburden load $P_{0}$ above the roadway of the workface can be any load that satisfies $P_{1} \geq 0$, which is $P_{0} \cos \alpha-\gamma y \sin \alpha \cos \alpha \geq 0$. Here, $P_{0}=10 \mathrm{MPa}$, Poisson's ratio of the main roof $\mu=0.25$, the main roof elastic modulus $E=30 \mathrm{GPa}$, the main roof thickness $h=6 \mathrm{~m}$, coal seam dip angle $\alpha=40^{\circ}$, strike length of the main roof $a=60 \mathrm{~m}$, and dip length $b=140 \mathrm{~m}$. The principal stress distribution in the thin main roof is shown in Figure 3.

It can be seen from Figure 3 that the principal stresses $\sigma_{\max }$ and $\sigma_{\min }$ in the upper-middle zone of the main roof in SDCS longwall workface are positive, indicating that the top roof $(z=-(h / 2))$ is compressed and the bottom roof is under tension. Meanwhile, $\sigma_{\max }$ and $\sigma_{\min }$ in the upper zone of upper boundary and left and right zones of vertical boundaries in the suspense zone are negative, implying that the top roof $(z=-(h / 2))$ is under tension, and the bottom roof is under compression. It shows that the bottom roof is under compression at three boundaries and tension in the middle zone, while the top roof is under tension at three boundaries and compression in the middle zone.

The maximum shear stress distribution in the main roof with the same parameters is depicted in Figure 4 . The maximum shear stress $\tau_{\max }$ occurs periodically in the uppermiddle zone of the main roof in the SDCS longwall workface as mining is advancing, and it is large in the middle but small on both sides. Since rock has a very low tensile strength, failure is likely to occur in the bottom roofs upper-middle zone. Both sides of the long boundaries of the top roof, as well as the upper zone of the short boundary, and the failure in the middle zone of the bottom roof will develop toward the long boundaries.

With the change of coal seam dip angle, the basic roof principal stress and the maximum value have a nonlinear correlation with the coal seam dip angle, and the principal stress decreases with the increase of coal seam dip angle. When the coal seam dip angle increases in the range of $30^{\circ}$ to $50^{\circ}$, the value decreases rapidly, which indicates that the dip angle has a great influence on the stress evolution of the thin layer; when the dip angle increases in the range of $50^{\circ}$ to $60^{\circ}$, the value decreases with the increase of coal seam dip angle. The change tends to be gentle, which indicates that the inclination angle has little effect on the basic top stress. 


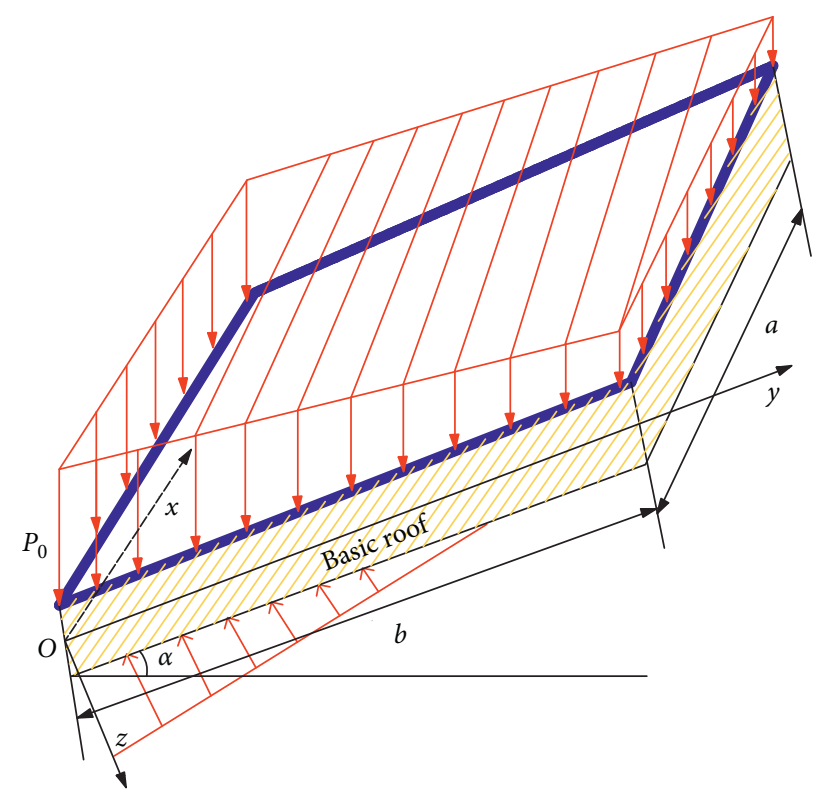

FIGURE 1: Mechanical model of the main roof in SDCS.
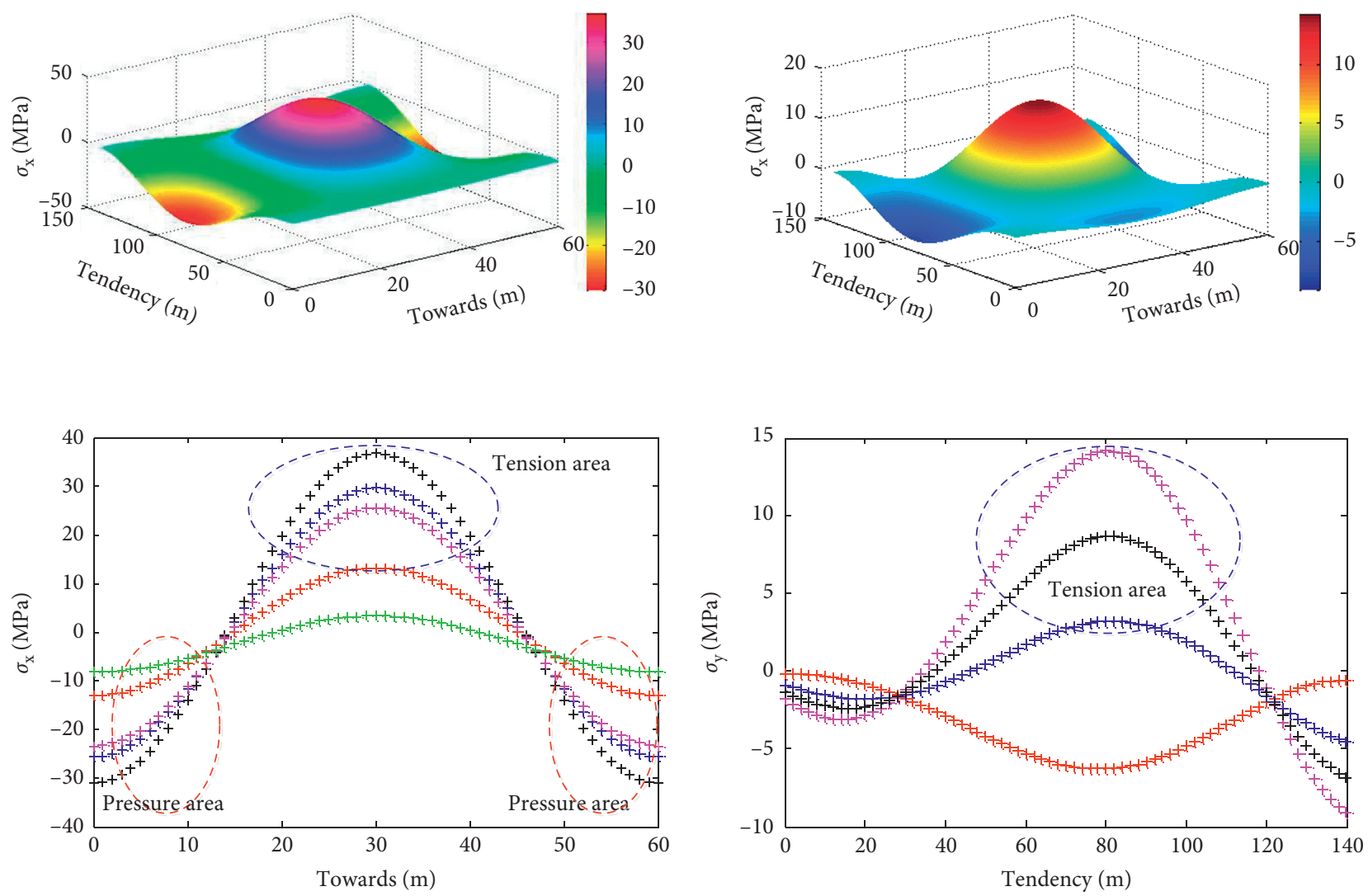
$+b=40$
$+b=100$
$+b=60$
$+b=120$

+. $a=5$

$+a=30$

$+a=15$

$+a=40$

(a)

(b)

Figure 2: Characteristics of $\sigma_{x}$ and $\sigma_{y}$ in the bottom floor of the thin plate. (a) $\sigma_{x}$. (b) $\sigma_{y}$. 


\section{Numerical Experiments}

In order to verify the accuracy of the theoretical model, numerical simulation is a scientific and effective research method. It is of great significance to establish a numerical simulation model based on a specific project to study the inclination effect of the evolution of the basic roof stress field in the mining process of steeply dipping coal seams.

4.1. Numerical Model. In order to further study the mining stress distribution and rock mass failure characteristics of coal seam with large angle, FLAC3D numerical models with coal seam dip angles of $30^{\circ}, 45^{\circ}$, and $60^{\circ}$ were established. The size of the numerical model $(x \times y \times z)$ is $180 \mathrm{~m} \times 300 \mathrm{~m} \times 400 \mathrm{~m}$, and the Mohr Coulomb constitutive model is used in the numerical calculation. The vertical displacement is limited at the bottom of the model, the horizontal displacement is limited around the model, and the stress boundary is at the top of the model. The buried depth of coal seam is calculated as $440 \mathrm{~m}$, and the stress applied on the upper part of the model is $7.5 \mathrm{MPa}$. The engineering geological conditions of workface with different coal seam dip angles are the same, the dip length is $130 \mathrm{~m}$, and the mining height is $4 \mathrm{~m}$. The physical and mechanical parameters of coal and rock are shown in Table 1 [29], and the numerical model (taking $45^{\circ}$ coal seam as an example) is shown in Figure 5.

4.2. Test Results. After the coal seam is mined, under the action of original rock stress and tectonic stress, the overlying strata break, rotate, and slide, and the stress of surrounding rock redistributes. The shape and size of vertical stress distribution are an effective index to evaluate the damage degree of overlying strata.

As shown in Figure 6, the overlying strata of $30^{\circ}, 45^{\circ}$, and $60^{\circ}$ coal seams show obvious arch-shaped stress release area (stress release arch). With the increase of coal seam dip angle, the arch height gradually decreases and continuously transfers to the upper air roadway of the working face $[30,31]$. When the dip angle of the coal seam is $30^{\circ}$, the vertical stress of the overlying strata is fully released, and the vertical stress concentration area is formed at the upper and lower roadway positions (both sides of the arch foot) of the workface. The vertical stress concentration range and concentration degree of the lower part of the workface (lower arch foot) are higher than that of the upper part of the workface (upper arch foot). With the increase of coal seam dip angle, the vertical stress concentration range and concentration degree of the working face show different changes in the upper and lower roadway positions. The vertical stress concentration range and concentration degree of the upper part of the workface (upper arch foot) decrease with the increase of coal seam dip angle, the vertical stress concentration range of the lower part of the workface (lower arch foot) increases with the increase of coal seam dip angle, and the degree of vertical stress concentration decreases with the increase of coal seam inclination.

In the mining process of inclined coal seam, with the increase of coal seam dip angle, the normal component of overlying strata gravity decreases and the tangential component increases. After the coal seam is mined, the shear downward trend of the overlying strata is enhanced, and the shear stress evolution law of inclined coal seam mining is very important [32]. The maximum shear stress can be used as an effective evaluation index of shear failure trend and location.

The maximum shear stress distribution of different coal seam dip angles is shown in Figure 7. It can be seen from the figure that there is an obvious arched shear zone (shear stress arch) in the overlying strata. The height of shear stress arch decreases with the increase of coal seam dip angle, the shear stress increases with the increase of coal seam dip angle, and the shear trend increases with the increase of coal seam dip angle. The upper and lower roadway position (both sides of the arch foot) forms a shear stress concentration zone, the upper part of the workface (upper arch foot) shear stress concentration range and concentration degree are higher than the lower arch foot. With the increase of coal seam dip angle, the range and degree of shear stress concentration in the upper and lower roadway show different characteristics. The range of shear stress concentration in the upper part of the workface (upper arch foot) decreases with the increase of coal seam dip angle, the degree of shear stress concentration increases with the increase of coal seam dip angle, and the shear stress concentration range and degree of the lower part of the workface (lower arch foot) decrease with the increase of the coal seam inclination angle.

The maximum principal stress distribution of different coal seam dip angles is shown in Figure 8. The maximum principal stress of the overlying strata of $30^{\circ}, 45^{\circ}$, and $60^{\circ}$ coal seams presents asymmetric distribution. The maximum principal stress of the upwind lane is greater than that of the lower machine lane, and the upper and lower lanes form stress. In the concentration area, the maximum principal stress concentration degree and concentration range decrease with the increase of the inclination angle. In the wind tunnel area on the working face, the maximum principal stress decreases with the increase of the inclination angle. The maximum principal stress is when the inclination angle of the coal seam is $30^{\circ}$. In the tunnel area under the working face, the maximum principal stress increases with the increase in the inclination angle.

With the advance of the workface, the complete structure of the overlying strata is deformed and damaged, and the shape of the failure area is different with the change of the coal seam dip angle [33,34]. As shown in Figure 9, the overlying strata of the working face present stepped plastic failure, the upper rock mass of the stepped failure line (white mark line in the figure) is complete, and there is no macroscopic failure such as mining fracture. The plastic failure area of the overlying strata presents a "hump shape," and the "hump shape" plastic failure pattern gradually transfers to the lower part with the increase of coal seam dip angle [35]. The shear plastic failure ability of overlying strata increases with the increase of coal seam dip angle, and the plastic failure range decreases with the increase of coal seam dip angle. 

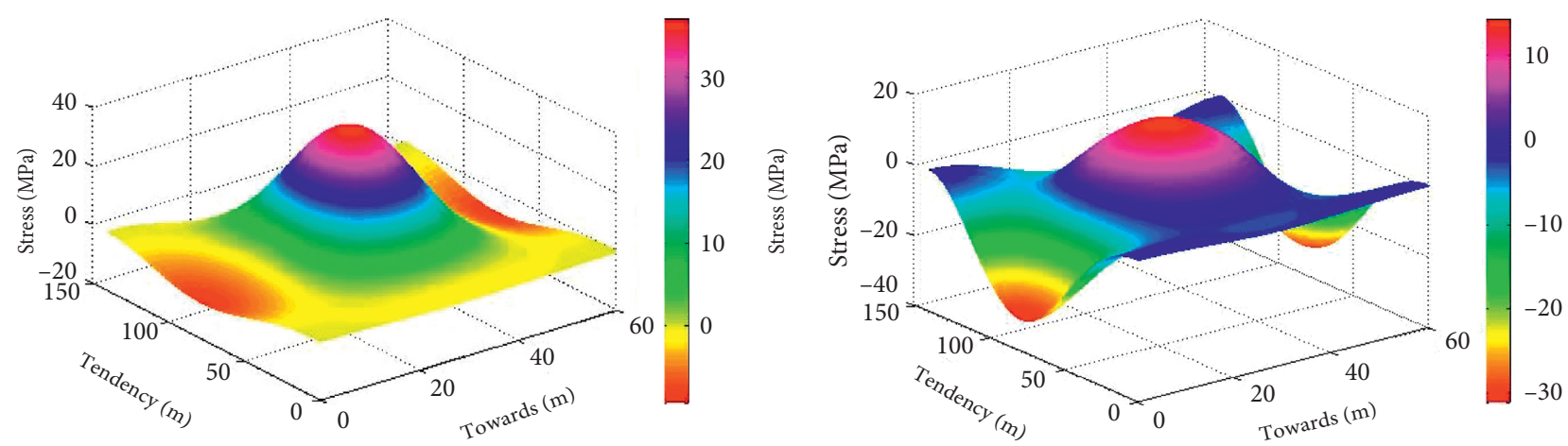

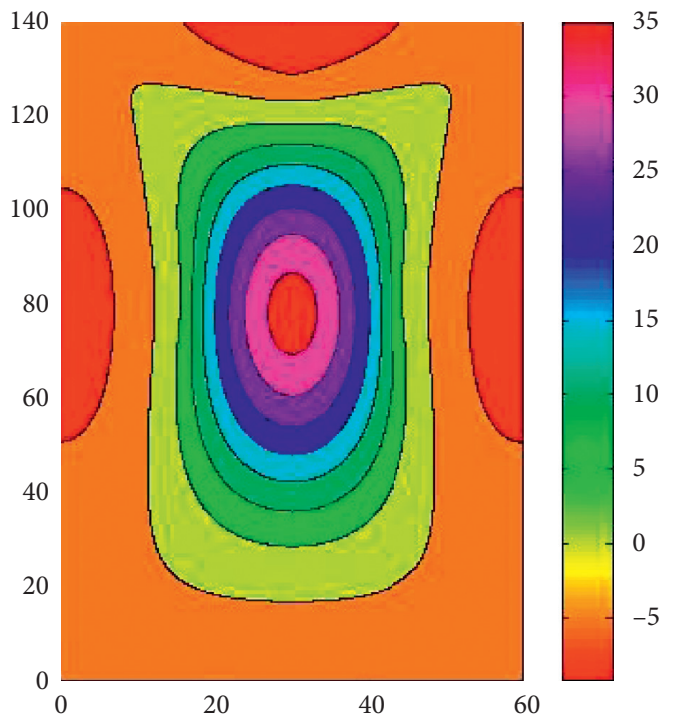

(a)

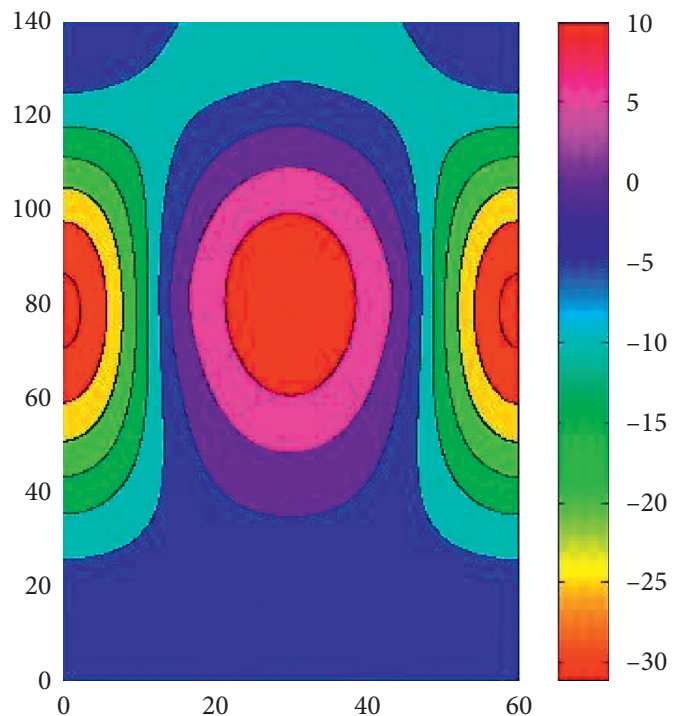

(b)

FIgURE 3: Neophogram of the principal stress in the main roof. (a) $\sigma_{\max }$ (b) $\sigma_{\min }$.
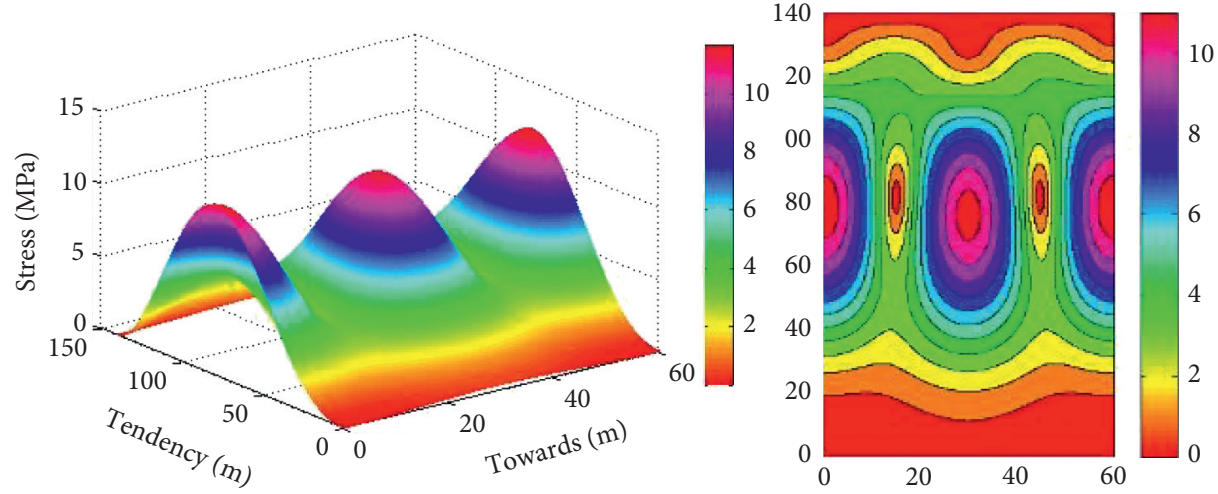

FIGURE 4: Neophogram of maximum shear stress of the main roof.

In the mining of steeply dipping coal seam, the surrounding rock stress is redistributed, forming a stress arch in the stable rock above the stope, which is symmetrical along the strike and asymmetrical along the inclined direction. The stress change of the surrounding rock of the stope causes the overburden to show a symmetrical arch along the direction of the working face and an asymmetric arch along the direction of the working face.
Spatially, the falling arch is located in the rock strata with obvious movement in the overburden collapse zone and fracture zone. There is a "stress-fall" double-arch structure in the overlying rock in steeply dipping coal seam mining stopes. With the working face advances, it continues to evolve and develop, which is manifested as a cyclic process of failure-instability-stability of the rock structure under the action of the double-arch. 
TABle 1: Physical and mechanical parameters of coal and rock.

\begin{tabular}{|c|c|c|c|c|c|c|}
\hline Lithology & $\begin{array}{l}\text { Thickness } \\
(\mathrm{m})\end{array}$ & $\begin{array}{c}\text { Compressive strength } \\
(\mathrm{MPa})\end{array}$ & $\begin{array}{c}\text { Elastic modulus } \\
(\mathrm{GPa})\end{array}$ & $\begin{array}{c}\text { Cohesion } \\
(\mathrm{MPa})\end{array}$ & $\begin{array}{l}\text { Friction angle } \\
\text { (deg.) }\end{array}$ & $\begin{array}{l}\text { Poisson's } \\
\text { ratio }\end{array}$ \\
\hline $\begin{array}{l}\text { Medium } \\
\text { sandstone }\end{array}$ & 6 & 57 & 15 & 2.4 & 35 & 0.2 \\
\hline Fine sandstone & 7.2 & 70 & 18 & 2.6 & 30 & 0.18 \\
\hline Sandy mudstone & 6.8 & 35.6 & 9.5 & 1.2 & 38 & 0.28 \\
\hline Mudstone & 2.5 & 21.5 & 6.2 & 0.9 & 24 & 0.3 \\
\hline Coal seam & 4 & 13.4 & 5.8 & 0.62 & 20 & 0.35 \\
\hline Mudstone & 3 & 21.5 & 6.2 & 0.9 & 24 & 0.3 \\
\hline Sandy mudstone & 7.6 & 35.6 & 9.5 & 1.2 & 30 & 0.28 \\
\hline
\end{tabular}

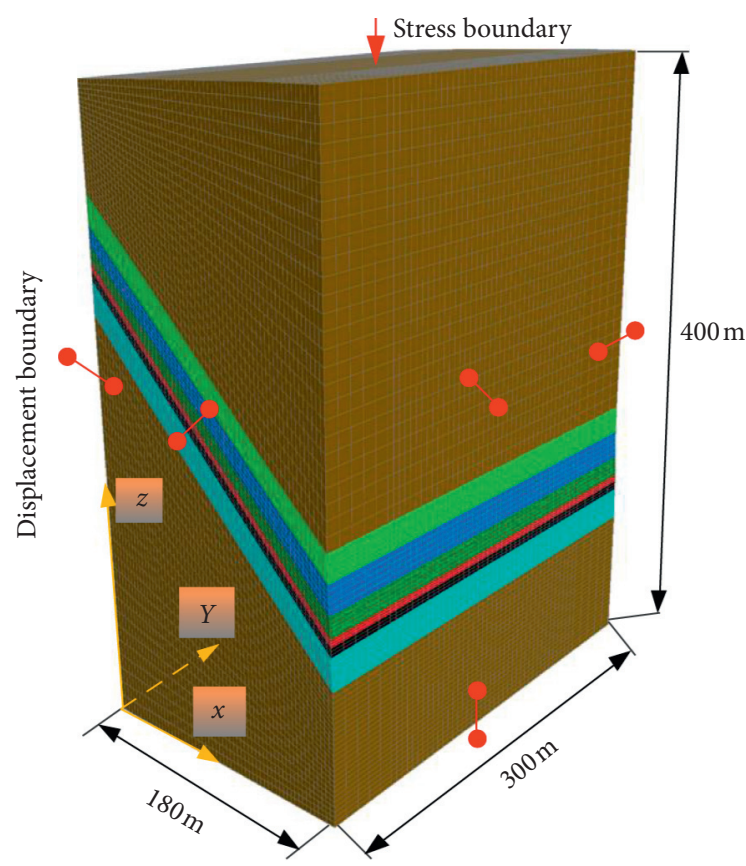

Figure 5: Numerical model.

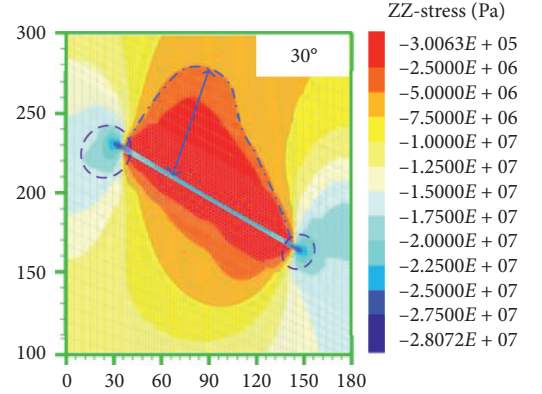

(a)

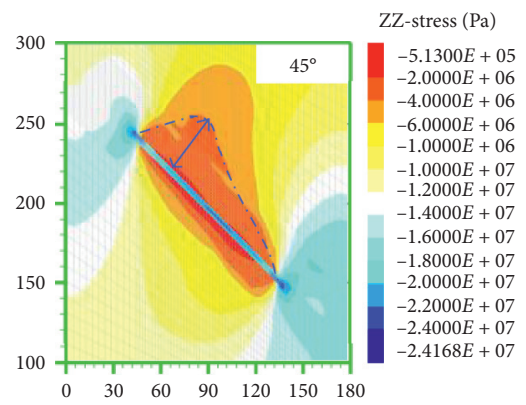

(b)

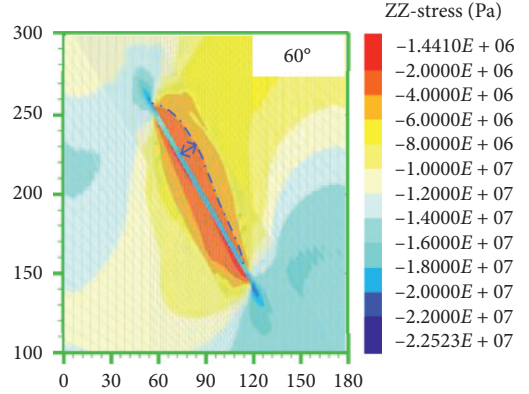

(c)

FIgURE 6: Vertical stress distribution characteristics of different coal seam dip angles.

\section{Analysis of the Support Stability}

Hydraulic supports are critical in protecting the roof and the dynamic mechanical environment where surrounding rocks impact and constrain each other [36-38]. The load magnitude, direction, and point of application to the support vary with the roof kinematic state changes. Therefore, determining the critical work resistance of support can ensure the particular mining requirements [39].

The mechanical model of a single inclined support is shown in Figure 10, where the $x$-axis is upward positive and coincides with the workface dip, the $y$-axis is upward positive and normal to the $x$-axis, $b$ and $h$ are the support width and height, respectively, h1 is the height of the support 


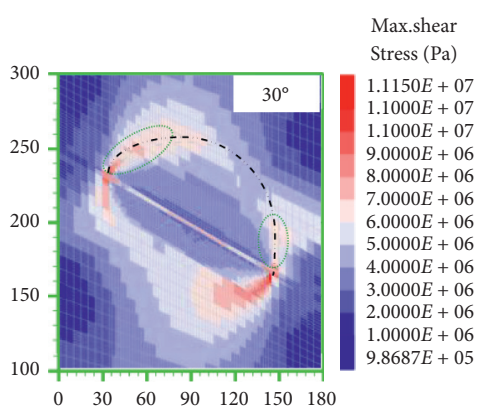

(a)

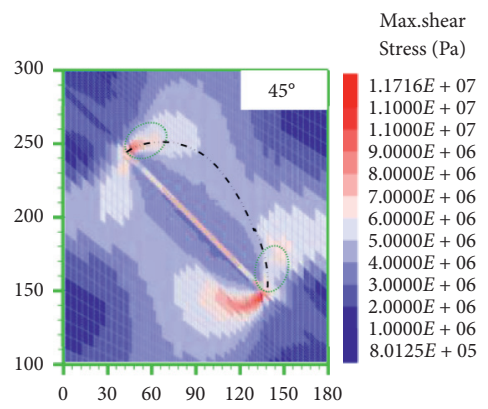

(b)

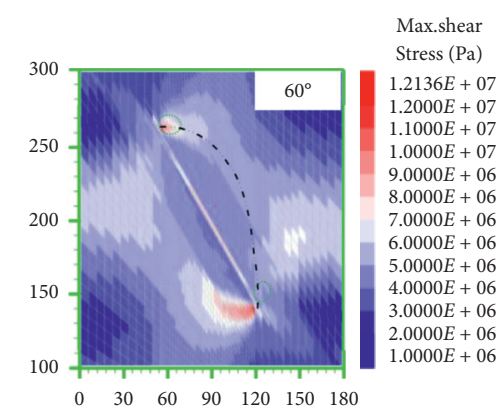

(c)

Figure 7: Distribution characteristics of maximum shear stress in different coal seam dip angles.

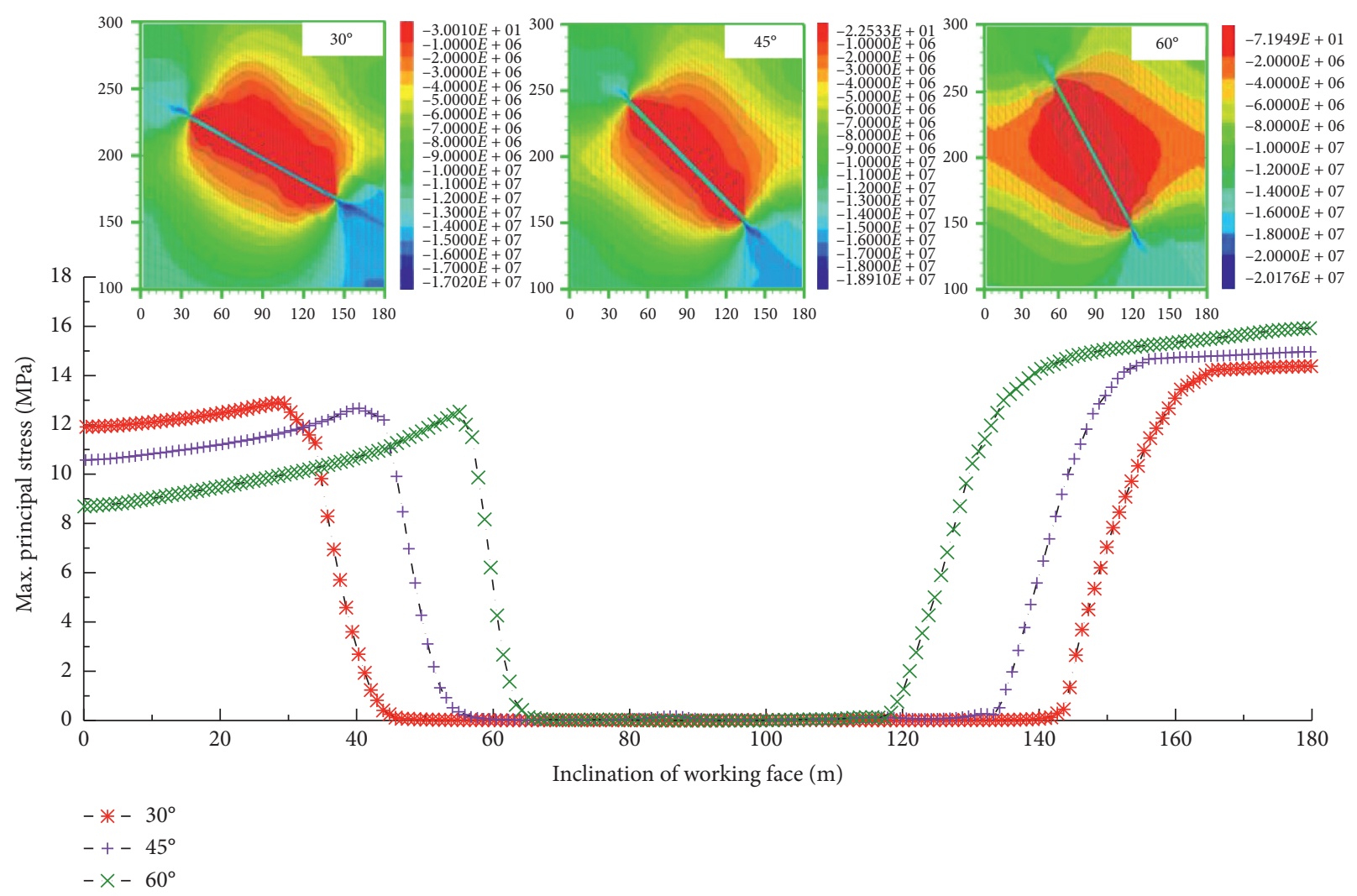

FIGURE 8: Distribution characteristics of maximum principal stress in different coal seam dip angles.

center of gravity, $x_{1}$ is the point of application of the normal load to the roof, $x_{2}$ is the point of application of the normal load resultant to the floor, $G$ is the support weight, $P$ is the normal load of the roof acting on the support (support work resistance), $f_{1}$ is the tangential load of the roof acting on the support (friction between roof and support), $F_{N}$ is the floor tangential load on the support, $f_{2}$ is the tangential load of the floor on the support (friction between support and floor), and $P_{i-1}$ and $P_{i+1}$ are forces acting between two adjacent supports. During mining in SDCS, forces between adjacent supports are much smaller than friction between support and roof or floor, so forces between adjacent supports are assumed to be the same. The mechanical response of the support in the critical instability state was analyzed in detail.
The critical work resistance of the support can be determined when the roof and floor are stable. To avoid sliding instability, the antisliding force should exceed the sliding force in the support, which means

$$
f_{1}+f_{2} \geq G \sin \alpha
$$

Under the critical sliding instability state, the coefficients of friction between the roof, floor, and support can be expressed as

$$
\begin{aligned}
& f_{1}=\mu_{1} P, \\
& f_{2}=\mu_{2}(P+G \cos \alpha) .
\end{aligned}
$$




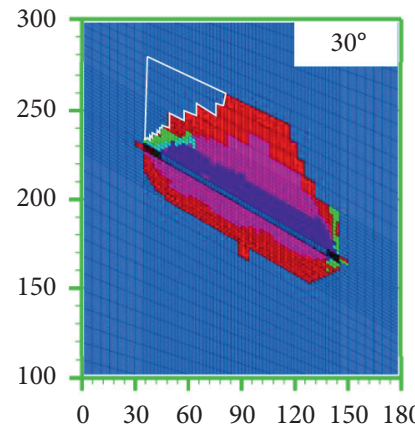

(a)

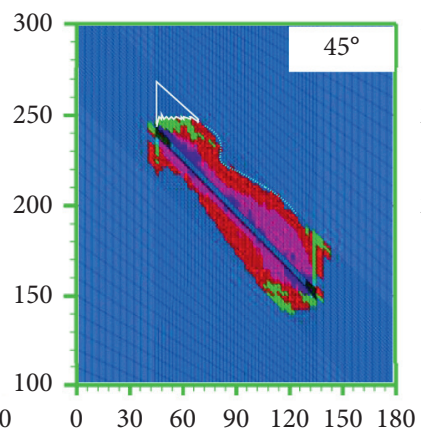

(b)

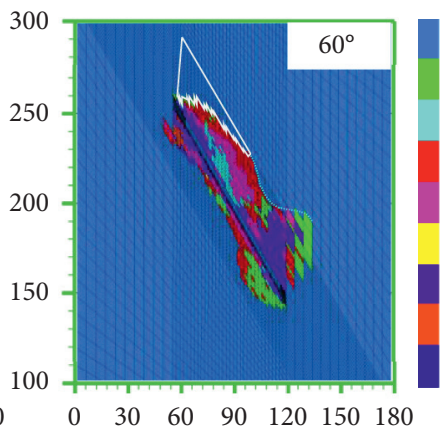

(c)

Figure 9: Distribution characteristics of the plastic zone in coal seam with different dip angles.

According to equations (14)-(16), the critical work resistance of a single support before sliding can be expressed as

$$
P_{\mathrm{sl}}=\frac{G\left(\sin \alpha-\mu_{2} \cos \alpha\right)}{\mu_{1}+\mu_{2}} \text {. }
$$

To avoid rotatory instability, the antirotating moment should exceed the turning moment, which means that

$$
\frac{b}{2} G \cos \alpha+P x_{1}+f_{1} h \geq h_{1} G \sin \alpha+F_{N} x_{2} .
$$

During mining in the workface, the loading characteristics of the support, roof, and floor change with time due to the roof and floor movements. When the support work resistance $P$ is applied to $A\left(x_{1}=0\right)$, the resultant force of normal loads on the floor $F_{N}$ has a point of application $C$ $\left(x_{2}=0\right)$; the support experiences the worst condition before nonrotatory instability. In this case, equation (18) can be reduced to the following form:

$$
\frac{b}{2} G \cos \alpha+f_{1} h \geq h_{1} G \sin \alpha .
$$

According to equations (16)-(19), the critical work resistance for single support before rotating can be expressed as

$$
P_{\text {ro }}=\frac{2 h_{1} G \sin \alpha-b G \cos \alpha}{2 h \mu_{1}} .
$$

As a case study for the proposed method, the 12123 workface in the Pansidong Coal Mine was selected to investigate the impact of the dip angle of coal seam on the critical work resistance of support analyzed via equations (17) and (20).

The 12123 workface in the Pansidong Mine is fully mechanized, with the average dip angle of the coal seam $\alpha=40^{\circ}$. A ZZ7200/22/45 covering hydraulic support was adopted in the workface, the support width was $1.5 \mathrm{~m}$, the height of the center of gravity of support was $h 1=2.25 \mathrm{~m}$, the gravity of support was $176.4 \mathrm{kN}$, the coefficients of friction between the support and roof/floor were equal $\left(\mu_{1}=\mu_{2}=0.25\right)$. The relationship between the critical work resistance of the support and the dip angle is shown in Figure 11, where the dip angle ranges from $20^{\circ}$ to $70^{\circ}$. It can be seen from Figure 11 that before slip and rotation of the

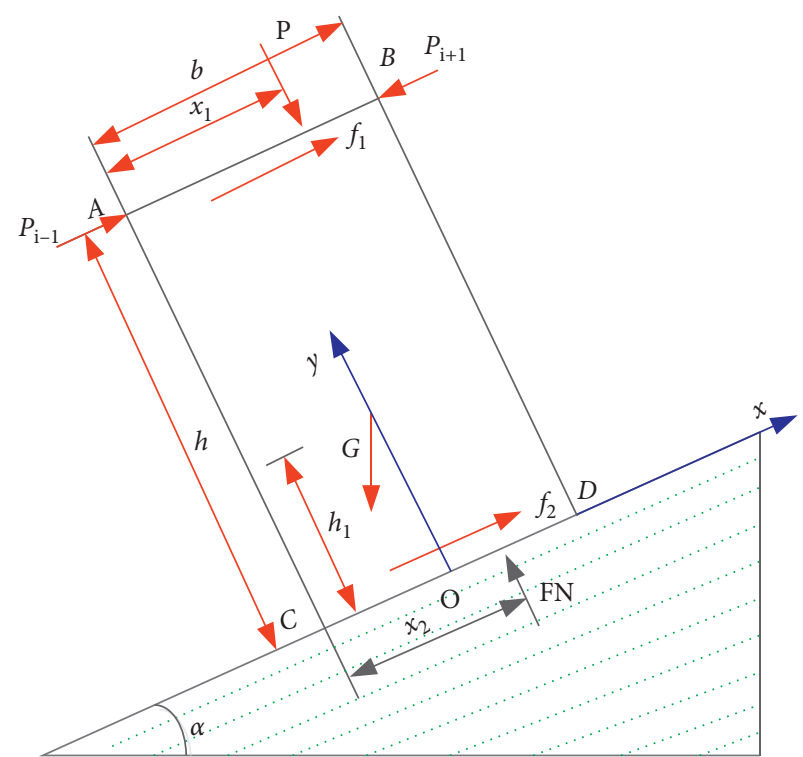

Figure 10: Mechanical model of a single inclined support.

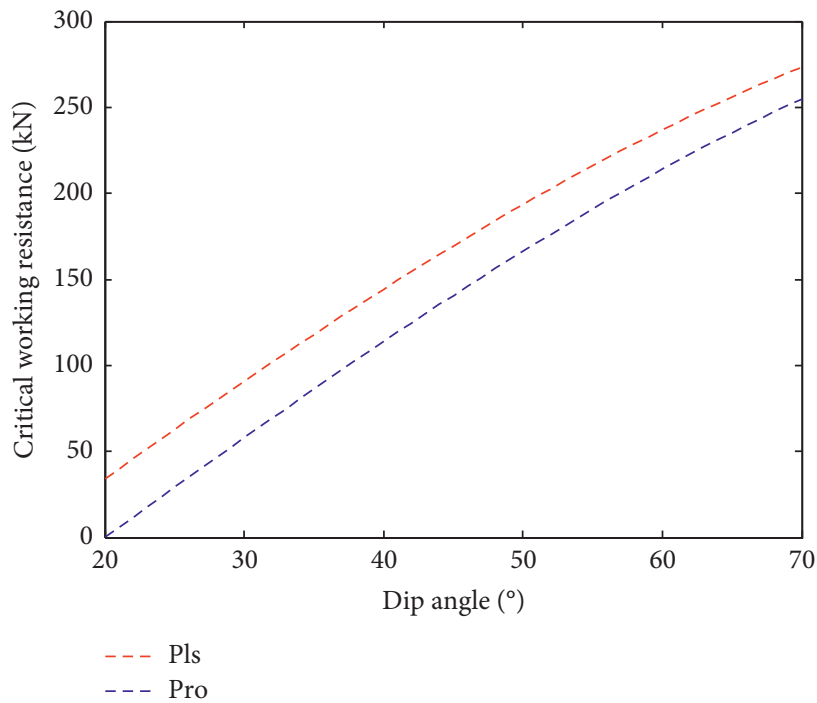

FIGURE 11: Relationship between the critical work resistance and dip angle of the coal seam. 
support, the critical work resistance of the support was positively correlated with the dip angle of coal seam and, under the same dip angle, the critical slip work resistance of support exceeded its critical rotation work resistance.

\section{Conclusions}

The results obtained made it possible to draw the following conclusions.

(1) A mechanical model of the main roof under linear load in the SDCS longwall workface was proposed in this study, which made it possible to derive the main roof stresses. The results obtained show that the bottom floor had features of compression at three sides and tension on the middle part, whereas the top floor had tensile stresses at three sides and compressive stress in the middle area. The maximum shear stress $\tau_{\max }$ slightly exceeded the middle of workface and occurred periodically during the workface advance.

(2) The main principal stresses $\sigma_{\max }$ and $\sigma_{\min }$ of the roof were nonlinearly correlated with the dip angle. When the dip angle increased in the range $30^{\circ} \sim 50^{\circ}$, $\sigma_{\max }$ and $\sigma_{\min }$ rapidly dropped; when the dip angle increases in the range $50^{\circ} \sim 60^{\circ}$, they gradually become stable.

(3) When the coal seam inclination angle is small, the overburden strata will fail and lose stability under the action of compressive stress, and the destruction depth of the overburden strata will gradually increase, showing the characteristics of gradual failure. When the coal seam inclination angle increases, the overburden fracture stress is driven by compressive stress to shear. The stress changes, showing sudden failure.

(4) The critical work resistance of a support under nonsliding and nonrotating conditions was positively correlated with the coal seam's dip angle. In sliding condition, the critical work resistance is bigger than it in rotating condition at the same dip angles of the coal seam.

\section{Data Availability}

The data used for conducting classifications are available from the corresponding author author upon request.

\section{Conflicts of Interest}

The authors declare that there are no conflicts of interest regarding the publication of this paper.

\section{Acknowledgments}

The authors acknowledge the financial support for this work provided by the China National Key Research and Development Program (2019YFC1904304) and the National Natural Science Foundation of China (Grant no. 51634007).

\section{References}

[1] Y. P. Wu, K. Z. Liu, D. F. Yun, P. S. Xie, and H. W. Wang, "Research progress in safe and efficient mining technology for large inclined coal seams," Journal of China Coal Society, vol. 39, no. 8, pp. 1611-1618, 2014.

[2] Q. Ye, W. J. Wang, G. Wang, and Z. Z. Jia, "Numerical simulation on tendency mining fracture evolution characteristics of overlying strata and coal seams above working face with large inclination angle and mining depth," Arabian Journal of Geosciences, vol. 10, no. 4, p. 82, 2017.

[3] Y. P. Wu, P. S. Xie, H. W. Wang, and S. G. Ren, "Surface oblique masonry structure of overlying strata in mining of large dip angle coal seam," Journal of China Coal Society, vol. 35 , no. 8, pp. 1252-1256, 2010.

[4] H. S. Tu, D. F. Zhu, D. Y. Hao, and K. J. Miao, "Force-fracture characteristics of the roof above goaf in a steep coal seam: a case study of xintie coal mine," Geofluids, vol. 2019, Article ID 7639159, 11 pages, 2019.

[5] J. R. Kang and J. Z. Wang, "Analysis of mechanical model of mining overburden and fracture failure conditions," Journal of China Coal Society, vol. 1, pp. 16-20, 2002.

[6] F. Shi, H. T. Wang, and C. Shu, "Similar simulation test research on the influence of coal seam dip on the deformation law of mining overburden," Journal of Chongqing University, vol. 41, no. 12, pp. 36-45, 2018.

[7] P. F. Shan and X. P. Lai, "An associated evaluation methodology of initial stress level of coal-rock masses in steeply inclined coal seams, Urumchi coal field, China," Engineering Computations, vol. 37, no. 6, 2020.

[8] Z. Hu, "Special issue on land reclamation in ecological fragile areas," International Journal of Coal Science \& Technology, vol. 5, no. 1, pp. 1-2, 2018.

[9] S. Zhang, X. Wang, G. Fan, D. Zhang, and C. Jianbin, "Pillar size optimization design of isolated island panel gob-side entry driving in deep inclined coal seam-case study of Pingmei no. 6 coal seam," Journal of Geophysics and Engineering, vol. 15, no. 3, pp. 816-828, 2018.

[10] A. J. Das, P. K. Mandal, R. Bhattacharjee, S. Tiwari, A. Kushwaha, and L. B. Roy, "Evaluation of stability of underground workings for exploitation of an inclined coal seam by the ubiquitous joint model," International Journal of Rock Mechanics and Mining Sciences, vol. 93, pp. 101-114, 2017.

[11] X. L. Chi, K. Yang, and Q. Fu, "Analysis of regenerated roof and instability support control countermeasures in a steeply dipping working face," Energy Exploration Exploitation, vol. 38 , no. $5,2019$.

[12] C. Xin, F. Du, K. Wang, C. Xu, S. Huang, and J. Shen, "Damage evolution analysis and gas-solid coupling model for coal containing gas," Geomechanics and Geophysics for GeoEnergy and Geo-Resources, vol. 7, no. 1, 2021.

[13] Y. C. Yin, J. C. Zou, Y. B. Zhang, Y. Qiu, K. Fang, and D. M. Huang, "Experimental study of the movement of backfilling gangues for goaf in steeply inclined coal seams," Arabian Journal of Geosciences, vol. 11, no. 12, 2018.

[14] X. F. Wang and M. Z. Gao, "Mechanical model analysis of roof breaking mechanism in variable length working face," Journal of China University of Mining and Technology, vol. 44, no. 1, pp. 36-45, 2015.

[15] J. Q. Jiang, P. P. Zhang, L. S. Nie, H. X. Li, and W. D. Wang, "Fracture law and dynamic response analysis of high hard and thick rock formations," Chinese Journal of Rock Mechanics and Engineering, vol. 33, no. 7, pp. 1366-1374, 2014. 
[16] T.-B. Zhao, W.-Y. Guo, Y.-L. Tan, C.-P. Lu, and C.-W. Wang, "Case histories of rock bursts under complicated geological conditions," Bulletin of Engineering Geology and the Environment, vol. 77, no. 4, pp. 1529-1545, 2017.

[17] J. A. Wang and J. Jiao, "Criteria of support stability in mining of steeply inclined thick coal seam," International, "Journal of Rock Mechanics and Mining Sciences, vol. 100, no. 82, pp. 22-35, 2016.

[18] F. Cui, Z. Y. Lei, J. Q. Chen, B. Chang, Y. B. Yang, and C. L. Li, "Research on reducing mining-induced disasters by filling in steeply inclined thick coal seams," Sustainability, vol. 11, 20 pages, 2019.

[19] K. Wang and F. Du, "Coal-gas compound dynamic disasters in China: a review," Process Safety and Environmental Protection, vol. 133, pp. 1-17, 2018.

[20] J. C. Wang and Z. H. Wang, "Research on the stability of the basic roof structure under the initial pressure in the shallowburied thin bedrock high-strength mining face," Journal of Mining and Safety Engineering, vol. 32, no. 2, pp. 175-181, 2015.

[21] Y. D. Zhang, J. Y. Cheng, X. X. Wang, Z. J. Feng, and M. Ji, "Thin plate model analysis of roof fracture in large dip angle upward (pitching) stope," Journal of Mining and Safety Engineering, vol. 27, no. 4, pp. 487-493, 2010.

[22] C. Xu, L. Yuan, and Y. Cheng, "Square-form structure failure model of mining-affected hard rock strata: theoretical derivation, application and verification," Environmental Earth Sciences, vol. 75, no. 16, pp. 1-12, 2016.

[23] X. P. Shao, X. Li, L. Wang, Z. Y. Fang, B. C. Zhao, and Y. Q. Tao, "Study on the pressure-bearing law of backfilling material based on three-stage strip backfilling mining," Energies, vol. 13, no. 1, 2020.

[24] J. Sun, X. Liu, and T. Ren, "Overburden stability of an inclined backfill stope in the context of the nonlinear elastic mechanical properties of the backfill body," Environmental Earth Sciences, vol. 78, no. 24, 2019.

[25] P. J. Yang, Y. He, and W. B. Guo, "Disaster mechanism and prevention and control measures of huge thick hard magmatic rock overlying stope," Journal of China Coal Society, vol. 38, no. 12, pp. 2106-2112, 2013.

[26] Y. X. Zhao, X. Z. Wang, J. L. Zhou, Q. S. Li, and C. Zhang, "The influence of the basic top thickness-span ratio of fully mechanized mining face on its initial fracture instability," Journal of China Coal Society, vol. 44, no. 1, pp. 94-104, 2019.

[27] K. Yang, X. He, L. Dou, W. Liu, L. Sun, and H. Ye, "Experimental investigation into stress-relief characteristics with upward large height and upward mining under hard thick roof," International Journal of Coal Science \& Technology \& Technology, vol. 2, no. 1, pp. 91-96, 2015.

[28] K. Yang, S. Liu, C. A. Tang, Z. Wei, and X. L Chi, "The mechanism and prevention of coal wall slicing in long-distance protected seams across coal groups with multiple key layers," Journal of China Coal Society, vol. 44, no. 9, pp. 2611-2621, 2019.

[29] H. M. Li, H. G. Li, G. J. Song, and K. L. Wang, "Physical and mechanical properties of coal measure strata in Shendong mining area," Journal of China Coal Society, vol. 41, no. 11, pp. 2661-2671, 2016.

[30] Q. Yao, J. Zhou, and Y. Li, "Distribution of side abutment stress in roadway subjected to dynamic pressure and its engineering application," Shock and Vibration, vol. 2015, Article ID 7639159, 11 pages, 2015.

[31] G. X. Xie, J. C. Chang, and K. Yang, "Investigations into stress shell characteristics of surrounding rock in fully mechanized top-coal caving face," International Journal of Rock Mechanics and Mining Sciences, vol. 46, no. 1, pp. 172-181, 2009.

[32] K. Yang, X. L. Chi, and S. Liu, "Mechanism and control of hydraulic support instability in fully mechanized mining face in large inclined seam," Journal of China Coal Society, vol. 43, no. 7, pp. 1821-1828, 2018.

[33] F. Du and K. Wang, "Experimental and numerical study of coal-gas outburst: insights from coal-rock structure, gas pressure and adsorptivity," Natural Resources Research, vol. 29, pp. 2481-2493, 2020.

[34] F. Du and K. Wang, "Unstable failure of gas-bearing coal-rock combination bodies: insights from physical experiments and numerical simulations," Process Safety and Environmental Protection, vol. 129, pp. 264-279, 2019.

[35] C. Xu, Q. Fu, and X. Cui, "Apparent-depth effects of the dynamic failure of thick hard rock strata on the underlying coal mass during underground mining," Rock Mechanics and Rock Engineering, vol. 52, pp. 1565-1576, 2019.

[36] Y. Chen, D. Li, F. Jiang, L. Zhang, C. Wang, and S. Zhu, "Use of the equivalent mining height method for understanding overlying strata movement and stress distribution in an isolated coal pillar," Shock and Vibration, vol. 2020, Article ID 8820886, 12 pages, 2020.

[37] D.-X. Li, W. Liu, and C.-Z. Fan, "Dynamic characteristics of satellite solar arrays under the deployment shock in orbit," Shock and Vibration, vol. 2018, Article ID 6519748, 8 pages, 2018.

[38] S. H. Luo, Y. P. Wu, P. S. Xie, H. W. Wang, and H. Zhang, "Mechanical analysis of support stability in longwall mining with large inclined seam strike," Journal of China Coal Society, vol. 44, no. 9, pp. 2664-2672, 2019.

[39] Z. L. Ge, S. H. Li, Z. Zhou, Y. Y. Lu, B. W. Xia, and J. R. Tang, "Modeling and experiment on permeability of coal with hydraulic fracturing by stimulated reservoir volume," Rock Mechanics and Rock Engineering, vol. 52, pp. 2605-2615, 2018. 